\title{
O Problema da Transmissão do Conhecimento no Oriente-Ocidente
}

CIPPICIANI, Irani ${ }^{1}$

\section{Resumo}

Este artigo discorre sobre os processos de transmissão de conhecimento na tradição hindu, problematizando as questões éticas, estéticas, técnicas e humanas implícitas no fenômeno; traçando paralelos com a experiência dos filósofos greco-romanos antigos e seus desdobramentos no contexto das artes cênicas contemporâneas.

Palavras-chave: transmissão de conhecimento, tradição, memória.

\section{Abstract:}

This article deals with issues related to the processes of knowledge transmission in the Hindu Tradition, discussing the ethical, aesthetic, technical and human issues, which are implied in the phenomenon; drawing parallels with the experience of ancient Greek and Roman philosophers and their consequences in the context of contemporary performing arts.

Keywords: transmission of knowledge, tradition, memory
1.

IRANI CIPPICIANI é atriz e bailarina formada em Artes Cênicas pela ECA - USP. Há 19 anos trabalha junto ao Grupo Caldeirão onde atua como atriz, arte-educadora, preparadora corporal e produtora, ajudando a administrar o Espaço Cultural Caldeirão. Há 15 anos é bailarina de dança indiana nos estilos Bharatanatyam, Kuchipudi e Mohiniyattam. Contato: iranicippiciani@uol.com.br 
A Índia, assim como muitos outros países orientais, é berço de tradições milenares sustentadas durante séculos quase que exclusivamente pela tradição oral. Especialmente no que tange as artes corporais, como o teatro e a dança, onde a representação viva do conhecimento é uma necessidade premente (ANTZE, 1995, p.30), a transmissão oral personificada na figura de um mestre, tornou-se eficiente instrumento pedagógico para a preservação da memória e da identidade cultural hindus, contribuindo de modo definitivo para a sobrevivência de inúmeras formas de arte tradicional na contemporaneidade.

O mestre ou Guru, como é chamado na Índia, é o sustentáculo ético, filosófico, espiritual, moral e estético da tradição. De sua conduta e habilidade dependerá não apenas a perpetuação de seu próprio nome, estilo e linhagem (Parampara), mas a perpetuação da própria forma de arte a que se dedica. o Guru é, portanto, aquele que incorpora o conhecimento passado de geração à geração e garante sua continuidade no curso da História, sem grandes desvios.

Este é, aliás, o ponto central de sua responsabilidade: a preservação de um conhecimento que vai além dele mesmo e que não deve ser maculado. Como diz Coomaraswamy:

\begin{abstract}
Os códigos de gestual e movimento prescritos para as diferentes partes do corpo eram obrigatórios para o ator; de tal modo que em matéria de gesticulação o termo 'originalidade' dificilmente pode ser aplicado. $O$ que é requerido do ator não é a sua interpretação de uma peça, mas a representação do mesmo, em conformidade com as regras prescritas. ${ }^{2}$ (COOMARASWAMY, 2006, p. 11, tradução livre).
\end{abstract}

Da necessidade de 'representar em conformidade com as regras prescritas' nascerão diferentes sistemas de ensino por toda a Índia, calcados sobre o tripé Devoção, Disciplina e Rigor. O Guru passa a ser então um pedagogo com a complexa tarefa de, não apenas transmitir códigos gestuais e corporais, mas de propiciar a construção de um outro corpo, uma outra natureza, a modificação integral do sujeito receptor. O treinamento terá, portanto, implicações que irão muito além do aprendizado técnico e chegarão ao cerne do sujeito, moldando também sua relação com o mundo em sua totalidade.

Nas artes, os mestres indianos tem nos dias atuais um recurso valioso a auxilia-los e guia-los neste processo. $\mathrm{O}$ tratado de artes conhecido como Natyasastra ${ }^{2}$, escrito entre os séculos IV AC e II DC. Trata-se de um compêndio grandioso que assegura as bases de transmissão do conhecimento, apre-
2.

"The code of gestures and movements prescribed for the different limbs was binding on the nata; so much so, that in the matter of gesticulation the term 'originality' can scarcely be applied to him, for what is required to him, is not his own interpretation of a play, but a representation of the same in accordance with the prescribed rules". (COOMARASWAMY, 2006, p. 11, tradução livre). 
sentando de modo detalhado os objetivos da experiência artística e os meios e modos de assegurar sua continuidade.

O Natyasastra mais do que um manual das artes performáticas ou um tratado estético, se propõe a investigar os pressupostos éticos expressos em suas páginas, o que o torna um coerente texto filosófico ${ }^{3}$ (KARNAD, 2007, p. ix, tradução livre).

Além das inúmeras histórias mitológicas, como os clássicos Mahabharata e Bhagavad Gita, onde exemplos da relação guru-discípulo estabelecem as bases éticas a serem seguidas na vida real.

Formar um artista dentro do sistema de sucessão discipular, o Guru Shishya Parampara, requer anos de investimento e uma sólida relação de confiança e entrega. Trata-se de uma relação um-a-um, que não se aplica a generalizações. Um Guru certamente terá mais de um discípulo, mas não é dado ao discípulo a escolha de ter mais de um mestre. Pelo menos, não simultaneamente ou num plano ideal de relação.

Ao Shishya, discípulo, cabe a responsabilidade de absorver corretamente os saberes de sua linhagem, como possível sucessor de seu mestre. Mas nem todo Shishya virá a ser um dia Guru. Os anos de trabalho e dedicação são tão intensos e exaustivos, exigem tantos sacrifícios pessoais, que nem todos os ingressantes chegam a concluir sua formação e, mesmo entre os que chegam, nem todos recebem de seus mestres o aval para darem prosseguimento à linhagem. Sem a benção e autorização do Guru, mesmo o discípulo mais dedicado, terá dificuldades em seguir adiante.

É certo que as rupturas entre mestres e discípulos sempre existiram e que discípulos renegados tenham criado, eles mesmos, linhagens importantes e duradouras, superando seus mestres. Mas estamos tratando de um projeto pedagógico ideal que, quando colocado em prática, estava sujeito a todo tipo de perversão, abuso e também novas soluções encontradas por cada mestre no dia-a-dia de seus Gurukulas (internatos).

É importante lembrar que o mestre não é apenas um professor especialista que ensina determinado conteúdo. Ele é uma referência moral, ética, para seus discípulos. Não é incomum que seja considerado como um segundo pai (ou mãe), ou mesmo que adote seu discípulo mais querido como filho. Ele dá conselhos pessoais, auxilia nos estudos, participa da escolha do esposo ou esposa e não raramente, pune o discípulo por faltas cometidas além do espaço de trabalho que compartilham.

A decisão de fazer de um discípulo sucessor em sua
3.

O Natyasastra, tratado da arte dramática hindu, escrito em sânscrito, é um dos mais antigos textos sobre a "ciência da representação e do gesto" na história da humanidade, cujo conteúdo apresenta informações relevantes à compreensão do surgimento e o propósito da arte teatral. Ele condensa referenciais teóricos, filosóficos, éticos, espirituais, técnicos e práticos que guiam os sistemas de ensino tradicional por toda a Índia. 
linhagem englobará todos esses aspectos, que contém muitos elementos objetivos e subjetivos. O que está em jogo vai muito além dos indivíduos ali envolvidos e diz respeito a preservação de um bem maior, que passa pelo tangível, mas atinge a esfera do invisível. A sobrevivência de uma visão de mundo e de homem, da memória coletiva de um povo e suas inquietações.

O Parampara, a linhagem é, portanto, um parâmetro sólido, que cria meios práticos para garantir a eficiência desse processo. Ela cria uma relação de colaboração espiral entre homens através dos séculos, retomando sempre os mesmos saberes em espaços-tempos diferentes, preservando não apenas a representação exterior de um determinado modo de olhar o mundo (a forma artística), mas, principalmente, garantindo a preservação de todo um universo de imagens coletivas arquetípicas que as sustentam e definem.

O Guru Shishya Parampara cumpre assim duas funções primordiais: a preservação de formas artísticas tradicionais no que tange a suas técnicas e procedimentos; e a perpetuação de uma visão particular de mundo, o Hinduísmo, onde a ordem humana e a ordem cósmica se completam.

É importante lembrar que essa relação no campo das artes, deriva da relação estabelecida entre os mestres espirituais e seus discípulos. A doutrina religiosa exige do ingressante um profundo grau de entrega e dedicação, sem as quais os segredos do mundo manifesto e não manifesto não lhes serão revelados e a liberação não será possível.

A arte é, portanto, uma outra forma de acessar esse manancial sagrado, dar vasão a necessidade humana de experimentar o desconhecido por meios controlados, simbólicos e imagéticos, de vivenciar o mundo transcendente a partir do mundo físico, sensorial. E por isso preserva muitas características que podem ser facialmente associada aos rituais religiosos e suas práticas.

O discípulo tem diversas obrigações para com seu mestre, desde aquelas que são materiais e monetárias, até obrigações mais comezinhas, como realizar pequenos favores cotidianos e domésticos. Mas muitas obrigações, assumem o status de ritual pela meticulosidade das ações que envolvem e pelo fato de que serão repetidas durante toda a vida comum entre ambos: fazer o pedido de permissão, oferecer a Dakshina, oferenda ao Guru, sempre que a formalidade de uma ocasião assim o exigir.

O discípulo deve sempre levantar-se quando o mestre chega, tocar seus pés como sinal de respeito, nunca chama-lo por seu nome, nem justificar-se quando for corrigido. Não deve queixar-se do rigor do treinamento, demonstrar cansaço ou dor física. Não deve encarar seu mestre quando este lhe 
chama atenção ou questionar suas decisões e escolhas, dentre uma lista enorme de outras obrigações que vão sendo estabelecidas no dia-a-dia, nas dinâmicas do próprio fazer, no um-a-um.

Ações que, a princípio parecem mero jogo de poder e dominação, subjugando o discípulo a autoridade do mestre, mas que, ao longo do tempo, revelam-se meios concretos de definir uma ética da relação, moldando o caráter do discípulo aos valores colocados pela tradição que não desconsideram os valores morais, filosóficos e religiosos que guiam a vida social e espiritual dos seus indivíduos.

Em retribuição, o mestre lhe transmitirá o saber de que é depositário e que dará ao discípulo a chance de elevar-se social e espiritualmente, levando adiante o nome de sua linhagem, o nome de seu mestre e o saber secreto de sua arte.

O Guru Shishya Parampara é um sistema claramente hierárquico e define com precisão os papéis de cada um de seus membros para minimizar ao máximo a possibilidade de insucesso. O mestre e o discípulo, cumprem seus papéis, o Dharma (dever) que lhes cabe. E onde o Dharma é corretamente vivenciado, segundo a tradição filosófica hindu, não há espaço para culpa ou arrependimento, e o sucesso é certo.

É interessante lembrar que os hindus elegem quatro objetivos centrais da experiência humana, conhecidas como Purusarthas: Kama (os prazeres sensuais), Artha (a prosperidade), Dharma (conduta moral e ética) e Moksha (a liberação espiritual). Estes objetivos que pertencem à toda a humanidade, são também aplicados à formação do discípulo tanto nos aspectos práticos e técnicos da apreensão da linguagem artística, quanto nos aspectos subjetivos de sua formação ética e espiritual.

Mas tudo isso estará diluído no próprio treinamento e será aprendido de forma indireta. Ao contrário de um mestre espiritual que tratará destes assuntos de modo direto, através do estudo das escrituras sagradas. No campo das artes, estas questões aparecerão nos mitos, nas diversas histórias sobre deuses, heróis, demônios e homens santos que os artistas interpretarão. No intuito de representar esses seres, dar-lhes vida e a apropriada forma externa, o discípulo e o mestre terão muitos embates filosóficos sobre cada mito, cada personagem e seus conflitos éticos e morais. O conhecimento transcendental e metafísico será agregado ao treinamento técnico deste modo e então talvez haja a necessidade de se recorrer às escrituras em busca de aprofundamento.

É comum no ocidente a crítica a esse sistema por ser considerado um modo autoritário de relação, que priva o aprendiz de sua autonomia crítica e estética, mas se nos abstivermos de 
estabelecer juízos morais sobre o que é mais correto ou apropriado em termos de pedagogia e didáticos, veremos que é um sistema que se provou extremamente eficiente através do séculos, dentro do contexto maior em que se insere.

As linhagens possuem nomes e árvores genealógicas próprias, através da qual identificamos as especificidades de determinado estilo e sua evolução na história, que é crítica e independente. É assim que ainda hoje podemos contextualizar determinado artista ou determinada corrente artística, seus maiores expoentes e contribuições mais significativas para a preservação do patrimônio cultural da Índia, no campo da dança e do teatro, por exemplo.

Nos dias atuais, quando os artistas estão sendo formados em grandes instituições de ensino, como a Kalakshetra e a Kerala Kalamandalam ${ }^{5}$, sob a tutela de diferentes mestres, numa estrutura de funcionamento que mescla elementos do modelo universitário ao Guru Shishya Parampara, as transformações decorrentes dessa mudança ainda não podem ser mensuradas.

De que modo afetarão a transmissão de conhecimento, a preservação da tradição e do ethos entre as gerações de artistas que se sucederão, é um terreno ainda novo e inexplorado.

É certo que há uma tentativa consciente de preservar o modelo do sistema tradicional, mantendo vivo alguns de seus preceitos mais importantes, mas é inegável que as mudanças estruturais interferem sobremaneira neste processo. A formação integral de um discípulo que antes durava uma vida inteira numa relação de profunda entrega e intimidade com seu mestre, segundo o sistema atual, se completa em 4 ou 6 anos. Os alunos saem formados das instituições, mas é difícil precisar se estão realmente preparados para serem instrumentos vivos e conscientes de perpetuação da tradição milenar que representam.

A tudo isso soma-se a influência do modelo ocidental de educação, em especial os modos de relação professor-aluno; as exigências do mercado e a alta competitividade que leva à posturas profissionais predatórias; o crescente número de estrangeiros praticantes, dentre tantas outras variantes que afetam diretamente a tradição e seus instrumentos de perpetuação.

De todo modo, é inegável que este sistema tenha impregnado de tal maneira a sociedade indiana, que resquícios dele apareçam nas mais diversas áreas e campos do saber, como algo já absorvido, um bem inquestionável, que se coloca em prática mesmo quando não é conscientemente acionado. Trata-se de uma precária e instável luta de forças, entre o poder de avançar da modernidade e o poder de perdurar da tradição.
5.

Kerala Kalamandalam e Kalakshetra Foundation são duas renomadas instituições do sul da Índia, engajadas no ensino de formas tradicionais clássicas e folclóricas de teatro, dança e música indianas. A primeira foi fundada em 1930 por Valathol Narayana Menon em Kerala, e a segunda em 1936 por Rukmini Arundale Devi, em Tamil Nadu. 
Segundo o filósofo Karl Jaspers (2011) houve um período da história humana, que vai de 800 a 200 AC, conhecido como Era Axial. Trata-se do período onde se colocaram 'as grandes questões filosóficas e espirituais por nós ainda respiradas' (JASPERS, p. 27), em lugares como Índia, Irã, China, Palestina e Grécia.

Este período foi marcado por um profundo paralelismo entre culturas que praticamente não tinham contato direto entre si, movidas por uma necessidade comum de transcender a vida material e entender a complexidade da existência, diante do terror da morte e da tomada de consciência de um sentido maior para a vida, além da experiência mundana.

Este momento histórico foi responsável pelo surgimento de importantes postulados éticos, morais e espirituais que, de algum modo, continuam a reverberar em nossas sociedades, tanto no oriente quanto no ocidente.

Enquanto na Índia, o Guru Shishya Parampara se estabelecia como sistema de elaboração dessas questões existenciais em diferentes campos do saber e da experiência humana, no ocidente, mais especificamente na Grécia, a Filosofia nascente também se ocupava das mesmas questões centrais.

A Filosofia Antiga, compreende um período que vai do século III AC até a queda do Império Romano e o início da Idade Média, e inclui diversas escolas de pensamento filosófico que, de algum modo, alicerçam todo pensamento filosófico posterior. No ocidente elas representam a experiência mais concreta que temos de um sistema de transmissão de conhecimento baseado na relação mestre-discípulo, regulado a partir de pressupostos éticos, morais, sociais e espirituais, visando a produção de saberes, a preservação de uma memória coletiva basicamente por meios orais e a elevação espiritual dos sujeitos envolvidos.

Durante esse período vemos florescer uma visão do homem inexoravelmente atado à natureza e ao cosmos, em busca de uma compreensão do mundo espiritual. Esta percepção metafísica do mundo tem implicações evidentes nos sujeitos e na pólis e acabam por determinar uma certa atitude moral do indivíduo (HADOT, 2006, p.236), exigindo instrumentos que fossem além do mero exercício de pensamento e chegassem ao campo da prática, transformando e moldando a conduta de seus indivíduos.

O conhecimento teórico sem uma prática que o sustentasse perdia, assim, seu valor inerente. Era preciso viver aquilo que se dizia: 
O carpinteiro não vem e diz: "Escute os meus argumentos sobre a arte da carpintaria", mas se compromete a construir uma casa e a constrói. Faça você o mesmo. (HADOT, 2006, p. 239, tradução livre) ${ }^{6}$

Isso significava tornar a Filosofia um ato existêncial, inaugurando o conceito de Filosofia como forma de vida, arte da existência (HADOT, 2006, p.240). Nas diferentes escolas filosóficas apareceram diversos métodos de execução deste ideal, todos eles baseados em exercícios práticos como aqueles que visavam a concentração da atenção através da meditação sobre dogmas fundamentais (HADOT, 2006, p.240) ou a elaboração do pensamento, através de métodos de conversação e debate, como aqueles colocados em prática por Sócrates e Platão, entre outros.

A essa prática sobre si mesmo, Hadot (2006) convencionou chamar de 'exercícios espirituais' e Focault (1984) de 'ética do cuidado de si', como podemos ver na entrevista "A ética do cuidado de si como prática da liberdade':

- Há então agora uma espécie de deslocamento: esses jogos de verdade não se referem mais a uma prática coercitiva, mas a uma prática de auto formação do sujeito.

- Isso mesmo. É o que se poderia chamar de uma prática ascética, dando ao ascetismo um sentido muito geral, ou seja, não o sentido de uma moral da renúncia, mas o de um exercício de si sobre si mesmo através do qual procura se elaborar, se transformar e atingir um certo modo de ser. Considero assim o ascetismo em um sentido mais geral do que aquele que lhe dá, por exemplo, Max Weber; mas está, em todo caso, um pouco na mesma linha. (FOCAULT, 2004, p.1)

Sem dúvida, essa elaboração exigia também a construção de um sistema de transmissão de conhecimento específico entre mestres e discípulos, a formulação de modos de relação, validação e perpetuação do conhecimento depositado nas diferentes escolas, assim como o Guru Shishya Parampara.

Infelizmente, não temos registros concretos de como estas relações pedagógicas se davam no plano do dia-a-dia mestre e discípulo. Podemos intuir alguns pontos nos escritos deixados pelos filósofos, mas não podemos afirmar que eles sejam provas concretas de um tipo de pedagogia aplicada ou apenas projeções idealizadas dessa relação, contendo algum fundo de verdade prática.

Fedro em seu discurso sobre as qualidades e a natureza do amor, fala sobre a relação do amado e do amante, como modelo ideal de relação entre homens para a realização do bem e do belo no mundo. A mesma compreensão ideal se estendia a relação mestre-discípulo, onde o mestre era visto como o amante e o discípulo como o amado:
6.

"El carpintero no viene y os dice: "Escuchad mis argumentaciones sobre el arte de la carpintería", sino que se compromete a construir una casa y la construye (...). $\mathrm{Haz}$ tu tambien lo mismo". (HADOT, 2006, p. 239, tradução livre) 
Pois não sei de bem maior que se pode proporcionar a um mancebo do que amá-lo virtuosamente, nem para um amante do que amar o objeto virtuoso. (PLATÃO, 2003, p. 103).

O aprendizado era idealmente, portanto, uma experiência amorosa, conduzida pelo mestre que instigava seus discípulos a formularem livremente seus próprios pensamentos e por seu próprio mérito e esforço pessoal, alcançarem a sabedoria. Mas não é possível afirmar que isso implicava necessariamente em modos de relação menos hierárquicos entre mestres e discípulos ou menos mediados por formalidades e obrigações, do que os exemplos vistos na Índia e no oriente como um todo.

O que sabemos certamente é que tratava-se de uma cultura da oralidade, onde a palavra, o discurso e a memória oral tinham valor inestimável para produção de conhecimento, assim como no Guru Shishya Parampara e que os debates calorosos aconteciam em assembléias, em praças públicas, nos banquetes, revestidos de pompa e de uma aura cerimonial, inseridos na vida da pólis e seus cidadãos.

É notável a concepção antiga de que o filósofo não era apenas aquele que desenvolvia um determinado discurso filosófico, mas aquele que vivia segundo seus padrões ético e morais, colocando em prática os ideais da escola de pensamento a que pertenciam.

Podemos dizer que a diferença entre a filosofia antiga e a filosofia moderna é que naquela não apenas Crisipo ou Epicuro são considerados filósofos, por terem desenvolvido alguma forma de discurso filosófico, mas qualquer um que vivesse segundo os preceitos de Crisipo ou Epicuro (...). Se trata de homens que se esforçam por realizar o ideal de sabedoria estóico, que supõe certa maneira de ser homem, de viver segundo a razão, de acordo com o cosmos e os demais homens. (HADOT, 2006, p. 245, tradução livre) ${ }^{7}$

Por motivos históricos que remontam ao fim do império romano e a ascensão do cristianismo, inaugurando o período Medieval, a Filosofia adquiriu outros contornos, desvinculando-se da ideia de uma arte da existência, cultivada pelo exercício sobre si.

Surgia a Teologia e a Mística Cristã para lidar com os assuntos da fé e da vida espiritual e a Filosofia ficava restrita a ciência fundamentada no exercício da razão, convertendo-se em atividade de caráter fundamentalmente teórico e abstrato. O próprio filósofo foi reduzido a figura de um especialista habilitado a formar outros especialistas, nas universidades nascentes. Somente entre os séculos XVI e XVIII veremos a Filosofia desprender-se desse estigma, revisitando alguns dos
7 .

Podría decirse que lo que diferencia la filosifía antigua de la filosofia moderna es que em aquélla no son sólo Crisipo o Epicuro los considerados filósofos, por haber desarrollado alguna forma de discurso filosófico, sino cualquiera que viva según los preceptos de Crisipo o Epicuro (...). Se trata de hombres que se esfurzan por realizar el ideal de sabiduría estoica, que suponen certa manera de ser hombres, de vivir según la razón, em acuerdo com el cosmos e los demás hombres. (HADOT, 2006, p. 245, tradução livre) 
postulados da Filosofia Antiga e atribuindo-lhes nova significação. (HADOT, 2006, p. 243).

Já a tradição oriental seguiu um caminho diverso. O Guru, que é o paralelo hindu do filósofo antigo, continua sendo o esteio ético e moral de uma determinada visão de mundo, mantenedor da memória oral e dos conhecimentos tradicionais. Um exemplo vivo de sabedoria e virtude a ser seguido. E a sabedoria de que dispõe não é apenas aquela referente a determinado ofício, mas uma sabedoria maior sedimentada num conhecimento que transcende a experiência material.

Outro ponto significativo é que o Guru Shishya Parampara estendeu-se por diversas áreas do saber: religião, arte, ciências e assim, encontrou um modo de sobreviver e persistir no tempo, fixando-se no subconsciente de seu povo como o modo ideal de aprendizado e de relação pedagógica. É fato que o sistema hindu nasceu associado à religião e mantém resquícios significativos de sua práxis.

O próprio hinduísmo é uma das vertentes religiosas mais coesas e pouco aberta à assimilação de influências externas. Os cultos seguem preceitos milenares detalhados e rigorosos, as escrituras sagradas são um bem maior inquestionável, os mantras são fórmulas imutáveis de contato com as forças espirituais que precisam ser memorizados à perfeição. Tudo na cultura hindu é projetado para perdurar, enquanto a Filosofia nunca teve esse mesmo propósito e, por isso, sempre esteve mais aberta e sujeita à mudança, as transformações e reviravoltas históricas.

Talvez isso explique porque, no Oriente, há tanta resistência a mudança, a interferência do sujeito sobre um conhecimento coletivo imemorial já sedimentado, enquanto no Ocidente, aceitamos com desconfiança a ideia de um conhecimento imutável e valorizamos mais a liberdade da experimentação à fixação rígida das formas e dos conceitos.

Mas é interessante pensar que ambas as experiências se firmaram no mesmo momento histórico, calcadas sobre inquietações comuns e buscando respostas para algumas questões humanas essenciais: a relação do homem consigo (Kama), com o outro (Dharma), com o mundo material (Artha) e com o mundo espiritual (Moskha).

A Filosofia Antiga e o ethos por ela implantada, deixou uma contribuição inegável para todo mundo ocidental e, de certa maneira, também incutiu em nós um modelo de relação professor-aluno, de aprendizado, que se reflete em muitas propostas pedagógicas modernas e contemporâneas. 
A história teatral do século XX, cujas reverberações atingem diretamente a produção cênica contemporânea, é marcada por um profundo sentido de renovação e experimentação. A ideia de que a arte teatral restringia-se a produção de espetáculos estava em desacordo com o projeto ideal de formação de um novo ser humano, de uma nova sociedade, de um novo teatro, que vigorava na Europa no começo do século.

Appia, Stanislawski, Fuchs, Craig, Meyerhold, Copeau, Reinhardt, entre outros, são nomes que figuram na história do teatro moderno como precursores de uma nova proposição artística: a necessidade de se criar uma cultura teatral, que implicava em organizar e sistematizar meios concretos de treinamento e formação que, não configurando um sistema ou método único e nivelador, fosse capaz de dar conta das demandas internas de cada companhia teatral engajada nesse novo projeto cultural.

Surgia então pela primeira vez a ideia de uma pedagogia teatral que se sedimentava sobre dois pilares: a investigação e fixação de algumas regras normativas para o treinamento e formação dos atores e a experimentação expressiva multidirecionada, aberta a muitas influências e diretrizes.

Eclodia uma profusão de escolas, ateliês, centros de pesquisa, laboratórios e estúdios formados por coletivos de artistas com interesses e inquietações comuns acerca da prática teatral. Diferentes didáticas e metodologias eram postas em prática com o objetivo de refletir o processo criativo, de modo livre, quase como uma espécie de auto pedagogia. Não havia um guia prático a seguir, um manual que estabelecesse os parâmetros para a criação cênica, cada centro de pesquisa criava suas próprias estratégias de transmissão de conhecimento e aprendizado, segundo suas próprias necessidades e descobertas.

Hoje compreendemos a importância desses locais para a produção de uma certa vanguarda teatral, conectada com a ressignificação do teatro num momento histórico onde as mudanças sociais aconteciam de forma extremamente rápida e brutal, diante dos olhos atônitos da sociedade. Era também um momento de grande otimismo, as utopias apontavam para a realização de um futuro promissor, de um homem e sociedade renovados.

Nesse contexto, criar espetáculos já não era o bastante. Produzir uma pedagogia do teatro era essencial para conectar a arte teatral à atmosfera social reinante. Não bastava mais ensinar teatro como na velha escola teatral, era necessário educar, nas palavras de Vakhtangov (CRUCIANI, 1995, p.26). 
Assim vemos nascer a figura de diversos diretores-professores envoltos no desafio de descobrir e definir não 'o que' ensinar, mas 'como' fazê-lo. Era necessário desmistificar a ideia de talento, do gênio teatral, e focar na experiência e maestria do intérprete que faz do treino o espaço de desenvolvimento de suas faculdades e potencialidades artísticas. Nada estava dado, tudo pedia o esforço e a elaboração consciente de debruçar-se sobre si e encontrar as respostas criativas mais adequadas.

Todas essas experiências eram feitas coletivamente, por grupos de artistas que alimentavam-se mutuamente, refletindo seus processos, reformulando ou fixando práticas, segundo sua aplicabilidade as demandas internas e a visão de teatro por eles estabelecida. A tônica era a transmissão do conhecimento essencialmente oral e prática, vivenciada no corpo e transmitida pela palavra.

\begin{abstract}
Devemos dar mais espaço e raízes mais profundas ao espírito da companhia, devemos encontrar estilos de vida que são favoráveis à profissão, uma atmosfera de formação intelectual, moral e técnica, uma disciplina, tradições. A renovação do teatro, que foi sonhada durante tanto tempo e que ainda está sendo invocada hoje, pareceu-me ser a primeira renovação do homem no teatro. (COPEAU, Jacques (1931), apud CRUCIANI, 1995, p. 28)
\end{abstract}

É certo que muitos diretores-professores e atores criaram seus cadernos de estudo, diários, livros de registro, onde podemos ver as práticas e propostas desenvolvidas, os questionamentos, os êxitos e os fracassos; e que isso cause em nós alguma identificação e sentido de pertencimento. Mas muito raramente podemos dar a estes escritos o caráter de método ou sistema de ensino teatral formal, ainda que isso tenha sido feito posteriormente. O que podemos afirmar com certeza é que eles estabeleceram parâmetros norteadores que ainda nos guiam e mobilizam e que são um instrumental válido na produção de nossos próprios métodos de treinamento, produção de espetáculos e reflexão sobre o processo criativo na contemporaneidade.

Nas experiências dos diretores-professores do século XX, podemos vislumbrar vestígios significativos de proposições provenientes da Filosofia Antiga como o surgimento de um novo homem de teatro, que podemos associar a concepção de transformação integral do sujeito, que assume uma postura ética diferenciada, uma conduta moral frente sua profissão e o mundo. A valorização da experimentação, centrada na prática, no esforço pessoal do artista, comprometido em transforma-se. Tudo isso sendo feito por coletivos de artistas engajados em repensar o 
homem, a sociedade, o cosmos, em centros de ensino que nos remetem às Academias gregas.

Ainda que não se possa falar numa tradição estabelecida, em um sistema de transmissão dos conhecimentos teatrais aplicável, suas experiências e descobertas configuram, para nós, uma espécie de tradição teatral ocidental, inaugurando a ideia de uma pedagogia do/para o teatro, que ainda influi sobre o modo como os artistas se agrupam e organizam e sobre a forma como a prática teatral e o próprio teatro são pensados em termos mais amplos.

Mas o oriente também trouxe contribuições significativas para desenvolver esse projeto de um novo homem de teatro no ocidente, exatamente por ter como ponto crucial aquilo que nos falta, uma tradição reguladora. No entanto, esse interesse sempre foi marcado por uma ambiguidade: o desejo de fundamentar uma tradição para o teatro no ocidente e a desconfiança dos métodos de fixação dessa tradição, no oriente. Em síntese, queremos a tradição sem abrir mão da experimentação, sem abdicar da ideia de um indivíduo independente que faz próprias suas escolhas estéticas, não subjugado a palavra e vontade absoluta de um mestre, de um modelo já estabelecido de antemão.

Queremos desenvolver sistemas de ensino como aqueles que vemos no Teatro Nô, no Teatro Kabuki, no Kathakali e nas danças dramáticas indianas, no Teatro Balinês, pautados pela tradição, que funcionam como um 'conjunto de bons conselhos' (BARBA, 1995, p. 8), sedimentados sobre códigos corporais e gestuais específicos, altamente refinados e elaborados.

Queremos o que essa experiência traz de ganho para a construção deste outro homem de teatro que passa, inevitavelmente, pela construção de uma outra corporeidade, uma segunda natureza do intérprete, uma visão de mundo específica, fundamentada na prática disciplinada à longo prazo, mas ficamos desconfortáveis diante dos meios que levam a isso.

Aqui avistamos dois pontos críticos: a ideia, ainda disseminada, de que um sistema fechado, baseado na repetição de códigos gestuais e movimentos preestabelecidos implica num empobrecimento das potencialidades expressivas do intérprete e a ideia de que a obediência ao mestre implica na perda de autonomia criativa e na dissolução da identidade do artista. Trata-se de um paradoxo entre forma e conteúdo, em termos pedagógicos. Aceitamos os conteúdos e reconhecemos seu valor em favor de nossos treinamentos e na produção de nossos espetáculos, mas não aceitamos com a mesma desenvoltura, a forma como eles se sedimentam. 
Mas o fervor pela livre experimentação nos impele ao oriente e um número crescente de artistas tem se dedicado a estudar suas formas de arte, tornando-se eles mesmos praticantes e, desse modo, a longo prazo, contribuindo para a desmistificação de alguns estigmas que ainda cercam a formação do artista oriental, como os expostos acima.

Na concepção oriental, a liberdade só existe pela prática da disciplina, pela repetição consciente e minuciosa das formas, que liberam a mente/espírito do praticante para estabelecer um contato mais profundo com o mundo físico e metafísico, de onde emana a experiência expressiva mais autêntica.

A autonomia criativa, por outro lado, nada tem a ver com o desejo permanente de originalidade, que parece uma tônica no ocidente. Ser autônomo não é criar sempre algo novo, como se o saber fosse algo que brotasse do nada e não fosse influenciado direta ou indiretamente por nossas experiências com outros seres, com a natureza, com o cosmos. Autonomia é a capacidade de diminuir a distância entre aquilo que se projeta no plano das ideias e aquilo que se constrói em termos de práticos, tem mais a ver com acuidade do que com inovação.

A identidade de um artista se define, portanto, por sua competência para corporificar essa visão de mundo e de homem, que a forma artística comporta. Ele não precisa ser original necessariamente, embora a originalidade não esteja descartada do processo ou seja renegada. Muitas vezes, os artistas descobrem formas diferentes de fazer um gesto, um movimento e tornam-se célebres por isso. A questão é valorizar mais a capacidade de comunicação, de colocar-se a serviço de algo maior que a experiência individual, à busca desenfreada da autoafirmação.

Se desejamos realmente nos beneficiar dessa aproximação com o oriente, é preciso combater enfaticamente a visão simplista de aprender uma técnica para coloca-la a serviço de nossos espetáculos, como se o exotismo da forma bastasse para configurar realmente uma nova estética, um novo pensamento teatral. O que está em jogo não é a estética da obra, mas o grau de profundidade da escuta de quem a realiza.

Se as técnicas não forem capazes de transformar o sujeito receptor, alterando não apenas suas potencialidades expressivas, mas a totalidade do seu ser, atingindo também quem o assiste, sua eficácia não será duradoura e seu valor estético, questionável. O que precisamos compreender é que, seja através da livre experimentação ou da obediência ao mestre, o que de fato importa é o que acontece no 'entre': entre o professor e aprendiz; entre a forma e o con- 
teúdo; entre o artista e o público; entre a arte e o mundo. É neste espaço abstrato, simbólico, impalpável, impossível de ser mensurado, mas tão concreto para nós quanto uma parede, que reside o cerne da experiência artística, o compromisso ético do artista para com a preservação de sua arte e o mundo a sua volta.

Posso ensinar-lhe o padrão gestual que indica olhar para a lua. Posso ensinar-lhe como fazer o movimento da ponta do dedo que mostra a lua lá no céu. Mas da ponta do dedo até a lua, a responsabilidade é inteiramente sua. (OIDA, 2001, p. 174) 
ANTZE, Rosemary Jeanes. "Exemplos Orientais". In: A arte secreta do ator. Dicionário de Antropologia Teatral. BARBA, Eugenio e SAVARESE, Nicola. São Paulo, Ed. Hucitec e Ed. Unicamp, 1995.

BARBA, Eugenio e SAVARESE, Nicola. A arte secreta do ator. Dicionário de Antropologia Teatral. São Paulo, Ed. Hucitec e Ed. Unicamp, 1995.

COOMARASWAMY, Ananda. "Introduction". In: NANDIKESVARA. Abhinayadarpanan. A Manual of Gesture and Posture used in Ancient Dance and Drama. Translation M. Ghosh. New Delhi, Manisha, 2006.

CRUCIANI, Fabrizio. "Exemplos Ocidentais". In: A arte secreta do ator. Dicionário de Antropologia Teatral. BARBA, Eugenio e SAVARESE, Nicola. São Paulo, Ed. Hucitec e Ed. Unicamp, 1995.

FOCAULT, Michel. "A ética do cuidado de si como prática da liberdade". In: Ditos \& Escritos V. Ética, Sexualidade, Política. Rio de Janeiro, Forense Universitária, 2004.

JASPERS, KARL. Introdução ao pensamento filosófico. Tradução Leonidas Hegenberg e Octanny Silveira da Mota. São Paulo, Cultrix, 2011.

HADOT, Pierre. Ejercicios Espirituales y Filosofia Antigua. Tradução J. Palácio Tauste. Madri, Siruela, 2006.

KARNAD, Girish. "Preface". In: SRINIVASAN, Amrit (Ed.). Approaches to Bharata's Natyasastra. New Delhi, Sangeet Natak Akademi and Hope India Publications, 2007. p. ix-xi.

PLATÃo. Apologia de Sócrates, O Banquete. Tradução Jean Melville. São Paulo, Martin Claret, 2003.

OIDA, Yoshi. O ator invisível. Tradução Marcelo Gomes. São Paulo, Beca, 2001. 